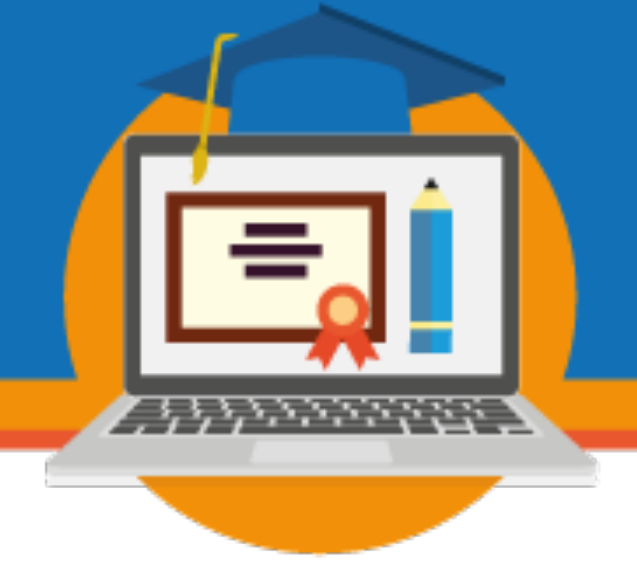

\title{
ANÁLISE DA POLÍTICA INSTITUCIONAL DO USO DE CARGA HORÁRIA A DISTÂNCIA NOS CURSOS PRESENCIAIS DO INSTITUTO FEDERAL GOIANO
}

\author{
Marina Campos Nori Rodrigues \\ Universidade Federal de Goiás \\ marinanori@gmail.com \\ Joseany Rodrigues Cruz \\ Universidade Federal de Goiás (UFG) \\ joseany.cruz@ifgoiano.edu.br
}

Eixo 5: Educação híbrida: uma tendência na educação superior

Resumo: O presente texto analisa a implantação da política de utilização de carga horária a distância em cursos presenciais do Instituto Federal Goiano. Foi realizada análise documental das Portarias publicadas pelo Ministério da Educação (MEC) que instituem e amparam tal prática. Realizamos, ainda, análise documental das regulamentações do IF Goiano para verificar o processo de implantação e situação atual da política institucional do uso de carga horária EaD nos cursos presenciais. Os resultados apontam que o ensino bimodal tem sido entendido pela instituição como uma estratégia de institucionalização da modalidade a distância, contudo, carece de maiores definições institucionais e planejamentos sistemáticos dos cursos e da instituição como um todo.

Palavras-chave: Institucionalização da EaD. Ensino Híbrido. Semipresencial.

\section{Introdução}

O presente texto visa analisar os documentos institucionais que amparam o uso de carga horária a distância no ensino presencial do Instituto Federal de Educação, Ciência e Tecnologia Goiano. O IF Goiano é uma instituição pública de ensino que atua desde o nível médio, com

\footnotetext{
${ }^{1}$ Resultado parcial de pesquisa que conta com apoio da Coordenação de Aperfeiçoamento de Pessoal de Nível Superior - Capes/ Fundação de Amparo à Pesquisa do Estado de Goiás - Fapeg e apoio do Conselho Nacional de Desenvolvimento Científico e Tecnológico - CNPq - Brasil.
} 


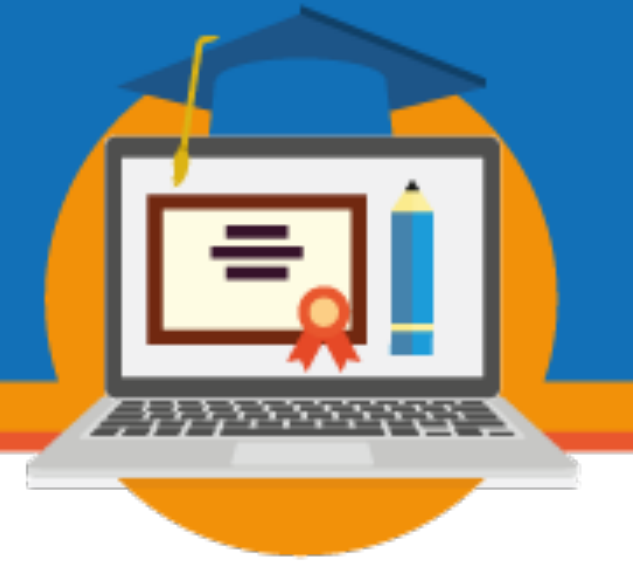

cursos técnicos, inclusive na modalidade EJA com o Programa Nacional de Integração da Educação Profissional com a Educação Básica (PROEJA), até cursos de doutorado. No site institucional ${ }^{2}$ identificamos que a instituição conta com 18 cursos técnicos de nível médio e 30 cursos de graduação, sendo eles: bacharelado, licenciatura e tecnológicos, e ainda 25 cursos de pós-graduação, incluindo cursos de especialização, mestrado profissional e acadêmico e doutorado acadêmico. O IF Goiano atende cerca de 15.000 alunos, em doze campi no estado de Goiás: Campos Belos, Catalão, Ceres, Cristalina, Hidrolândia, Ipameri, Iporá, Morrinhos, Posse, Rio Verde, Trindade e Urutaí.

Como recorte, escolhemos trabalhar com a legislação que subsidia o modelo semipresencial nos cursos de graduação. Segundo Silva, Maciel e Alonso (2017) o ensino híbrido foi possibilitado aos cursos de graduação pela publicação das portarias que subsidiam a prática do uso de carga horária a distância nos cursos presenciais. O ensino híbrido é apontado, por diversos pesquisadores, como uma das alternativas de atualização de práticas docentes, tornando-se uma das principais tendências da educação contemporânea.

\begin{abstract}
A integração entre o ensino presencial e o virtual vem sendo foco de estudo no cenário mundial, como demonstra Belloni (2012) ao enfatizar que "as tendências mais fortes indicam para o desenvolvimento de modelos institucionais 'mistos' ou 'integrados' por meio dos quais as instituições convencionais de ensino superior ampliarão seus efetivos e diversificarão suas ofertas” (p. 117).
\end{abstract}

$[\ldots]$

Nesse sentido, Horn e Staker (2015), corroboram Belloni (2012), ao afirmarem que o blended learning, mescla do ensino presencial com o ensino virtual dentro e fora da escola, já se consolidou como uma das tendências mais importantes da educação do século XXI. (Silva, Maciel e Alonso, 2017, p. 96)

Para tanto, abordamos os limites e possibilidades do uso da carga horária a distância nos cursos de graduação, compreendendo os conceitos que subsidiam a prática de uma educação que integre momentos presenciais e virtuais num mesmo currículo. Assim, analisamos as portarias que regulamentam esta prática, identificando conceitos que determinam a concepção de curso possível no cenário da legislação educacional, e em que medida as instituições podem

${ }^{2}$ www.ifgoiano.edu.br 
organizar um programa de curso que preveja a integração dos momentos presenciais e virtuais nos cursos de graduação. Desta forma, é necessário estabelecer a distinção entre os termos semipresencial e híbrido, pontuando as diferentes concepções que estão relacionadas ao uso de cada um deles.

$\mathrm{Na}$ segunda parte do texto, trazemos as primeiras análises sobre os documentos institucionais do uso da carga horária a distância nos cursos do IF Goiano, objetivando a verificação de como tal instituição concebe essa prática dentro dos currículos dos cursos presenciais e qual concepção de ensino bimodal vem sendo construída na instituição, à luz do que reflete o estabelecido nos documentos institucionais.

\section{Utilização de carga horária a distância nos cursos de graduação: conceitos que estabelecem a prática de ensino bimodal}

A adoção de carga horária presencial nos cursos de graduação foi introduzida na legislação brasileira em 2001, por meio da Portaria 2.031, de 18 de outubro de 2001, do Ministério da Educação. Em 2004, outra portaria foi lançada revogando a portaria anterior. Essa alteração na legislação referente à implantação de carga horária $\mathrm{EaD}$ possibilitou que instituições de ensino não-universitárias também pudessem atuar na aplicação de cursos denominados semipresenciais. Segenreich (2014) aponta que a implantação da carga horária dos $20 \% \mathrm{EaD}$ nos cursos presenciais foi uma resposta à pressão que as instituições de ensino particulares realizaram, junto ao poder público, para iniciar projetos com propostas de ensino híbrido.

Em 2016, foi lançado outro instrumento normativo da prática da semipresencialidade, ainda que o termo não seja mais citado no documento normativo, e nem em nenhum outro instrumento legal vinculado a modalidade a distância ou presencial. A alteração mais significativa do documento conta com a possibilidade de aplicação do ensino bimodal a qualquer curso de instituição que tenha ao menos um curso superior reconhecido pelo 
MEC. Em 2018, outro instrumento foi lançado aumentando o quantitativo de carga horária de $20 \%$ para $40 \%$ a distância nos cursos presenciais, que deveriam atender ao estabelecimento de alguns critérios relacionados, principalmente, às notas do curso e conceitos institucionais. No final de 2019, uma nova portaria foi publicada com foco específico nas instituições da Rede Federal de Ensino. De forma geral, a portaria retira os critérios que restringem o aumento para $40 \%$ do uso da carga horária de $\mathrm{EaD}$, estendendo esse aumento a todos os cursos, com exceção dos cursos na área da saúde. Contudo, faz referências a uma nota mínima no ato de avaliação dos cursos em áreas relacionadas à modalidade como metodologia, atividades de tutoria, uso das Tecnologias de Informação e Comunicação (TICs) e Ambiente Virtual de Aprendizagem (AVA). (Brasil, 2019)

Chamamos aqui de ensino bimodal a prática de integrar as modalidades a distância e presencial dentro de uma mesma proposta curricular, sem necessariamente ter uma integração para além das cargas horárias propostas a cada uma das modalidades. Essa perspectiva do ensino bimodal pode ser equiparada ao termo semipresencial presente nas legislações e ainda usada em textos acadêmicos que se referem a prática de integração de cargas horárias a distância e presenciais.

O modelo de ensino semipresencial ou bimodal é tido como sinônimo do Ensino Híbrido em muitos textos acadêmicos que tratam desta integração de cargas horárias de modalidades distintas. Contudo, a literatura nos mostra que o conceito de ensino híbrido foi se modificando, integrando a esta metodologia de ensino concepções que aprofundam o processo de hibridização para além da concepção dos espaços em que ocorrem o processo de ensinoaprendizagem.

No texto de Lencastre (2013) o autor nos mostra a evolução do conceito, indicando o ensino híbrido como uma metodologia de ensino e de aprendizagem na perspectiva da integração, que se estende a uma diversidade de combinações metodológicas e variedade de ações e lugares educativos, propiciado pela inserção das tecnologias educativas no contexto das escolas. Segundo o autor, conseguir a mistura e o equilíbrio adequados entre os meios e a 


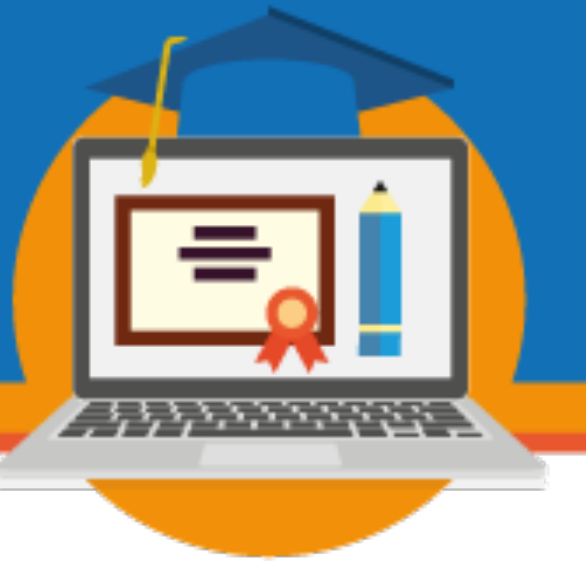

tecnologia, incluindo o uso da sala de aula, integrado num programa multimídia bem desenhado traz maiores probabilidades de sucesso desta metodologia.

Contudo, o que podemos observar ao analisar a legislação que regulamenta o ensino bimodal é somente o foco no uso da carga horária ora a distância, ora presencial. Uma vez que não existe uma definição legal de quais são os limites desta integração, os instrumentos de avaliação de curso acabam por avaliar os cursos que utilizam a integração das modalidades como um curso a distância, trazendo um enfoque substancial as ferramentas de TICs, bem como equipe específica de cursos da modalidade a distância.

De forma geral, como apontado por Silva (2016), as instituições públicas seguem reaplicando esse entendimento de junção de espaços educativos, referendando, também, o afrouxamento verificado nas portarias publicadas pelo MEC sobre a regulação das ações que envolvem o uso de carga horária a distância nos cursos presenciais.

\section{O uso de carga horária a distância no IF Goiano - trajetória e análise}

A utilização de carga horária a distância nos cursos presenciais do IF Goiano data de 2015, quando iniciou o processo de implantação do Campus Trindade. Todos os cursos presenciais que viriam a ser implantados nesse campus foram planejados a fim de contemplar a adoção de parte da carga horária a distância, numa ação pioneira na Instituição. Na época, a Diretoria de Educação a Distância elaborou um documento com orientações sobre a adoção da carga horária $\mathrm{EaD}$ nos cursos presenciais da instituição. Ainda sem a perspectiva de regular a prática, o documento de cunho orientativo acabou por ser incorporado com algumas modificações ao instrumento normativo da EaD que viria ser publicado em 2018.

Antes disso, em 2017, a Pró-Reitoria de Ensino do IF Goiano, subsidiada pelas ações do Núcleo de Ensino a Distância, iniciou a gestão de algumas ações institucionais para a adoção de carga horária a distância nos demais cursos da instituição. Inicialmente, foi acrescido ao 


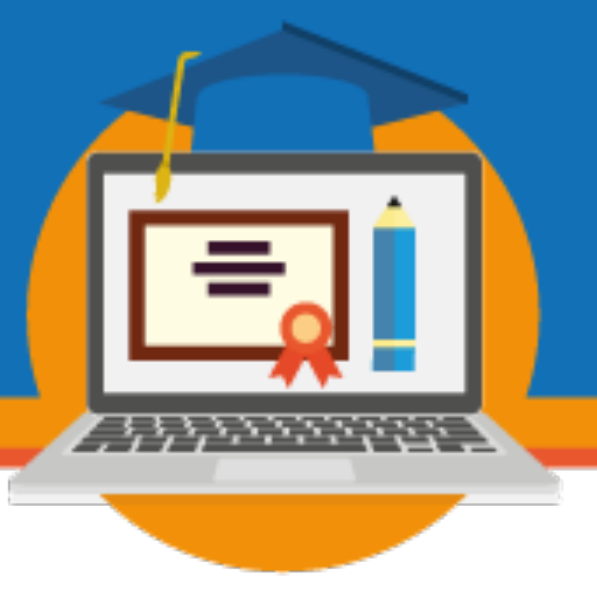

texto dos regulamentos de cursos do IF Goiano, tanto de nível médio como de graduação, a prerrogativa de utilização de carga horária a distância nos cursos presenciais, no limite de até $20 \%$ da carga horária do curso, conforme destacado abaixo.

Art. 64. As disciplinas dos cursos poderão ser oferecidas, no todo ou em parte, utilizando métodos não presenciais, num limite máximo de $20 \%$ (vinte por cento) da carga horária de cada curso, desde que a proposta da metodologia a ser empregada seja prevista no PPC. Parágrafo único. Para utilização da carga horária não presencial deverá ser observado o disposto em regulamentação específica do IF Goiano. (Brasil, 2017a).

Art. 76 - Respeitados os mínimos previstos de duração e carga horária total, o plano de curso técnico pode prever atividades não presenciais, até $20 \%$ (vinte por cento) da carga horária diária do curso, desde que haja suporte tecnológico e a proposta da metodologia a ser empregada seja previamente aprovada pelo Conselho do Curso e conste do PPC. Parágrafo Único - Para utilização da carga horária não presencial deverá ser observado o disposto nas Normas para oferta de Carga Horária Semipresencial em Cursos Presenciais do IF Goiano. (Brasil, 2017b).

Ainda em 2018 foi aprovado o primeiro Regulamento de Educação a Distância do IF Goiano. Esse documento passou a regular as normativas institucionais dos cursos EaD de nível médio e de graduação, além dos cursos de Formação Inicial e Continuada (FIC). Esse documento possui um capítulo específico que trata da carga horária a distância em cursos presenciais, que objetiva caracterizar a prática, bem como regular os procedimentos referentes à aplicação desta perspectiva curricular nas disciplinas e matriz do curso. Todas as cinco portarias publicadas sobre a utilização de carga horária $\mathrm{EaD}$ em cursos presenciais fazem referência à necessidade de atualização do PPC a fim de contemplar a adoção da carga horária EaD. Quanto à obrigatória alteração dos PPCs, encontramos a seguinte orientação:

Art. 75. A utilização da modalidade a distância deverá estar explicitada no Projeto Pedagógico de Curso (PPC) e especificada a carga horária de cada componente curricular na matriz.

$\S 1^{\circ}$ As especificações de carga horária e disciplinas que contemplarão momentos a distância deverão estar previstas em documentos anexos ao PPC.

$\$ 2^{\circ}$ Todos os cursos regulares do IF Goiano possuem a prerrogativa de alterar este item do PPC sem a necessidade de aprovações individuais pelo Conselho Superior.

$\S 3^{\circ}$ Esta alteração deve ser aprovada pelo Colegiado de Curso, ou Conselho de Curso, e ter a aprovação final da Diretoria de Ensino do campus.

$\S 4^{\circ}$ Os anexos do PPC, referentes aos planos de ensino das disciplinas, devem ser aprovados pelo coordenador do curso, sem a necessidade de aprovação de instâncias superiores. 


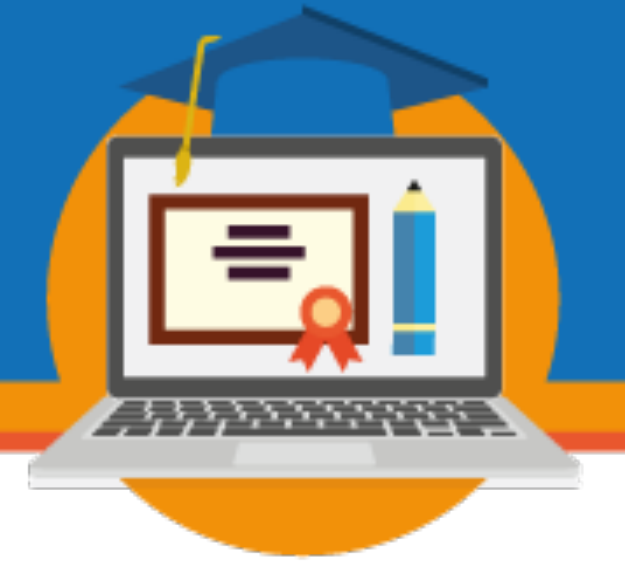

direcionamento, apontamos os estudos realizados por Silva (2016) que analisou a regulamentação das instituições públicas federais na implantação de propostas de ensino híbrido, balizadas pela Portaria $n^{\circ} 4.059$, de 10 de dezembro de 2004. A autora identifica diversas concepções adotadas institucionalmente sobre o que é e como desenvolver o ensino híbrido. Identificou também que as estruturas pedagógicas e organizações curriculares, em especifico na implantação do modelo semipresencial são muito dispares de instituição para instituição. A consequência desse afrouxamento regulamentar, como foi identificada por Silva, Maciel e Alonso (2017) como um voluntarismo das instituições que atuam na implantação do ensino híbrido a partir da adesão individual de professores.

Identificamos que esse voluntarismo também pode ser uma prática estabelecida no IF Goiano, quando a instituição permite no regulamento que as alterações de matriz devem ser incluídas no PPC como um anexo, precedida de uma análise conjunta e estrutural do NDE em relação à adoção de uma prática de ensino verdadeiramente híbrida, como apontada por Lencastre (2013).

Essa falta de informações sobre o formato semipresencial denota a autonomia impressa pelos regulamentos do ensino híbrido, corroborando o apontamento de Moran, Araújo Filho e Sidericoudes (2005), que caracteriza esses casos como voluntarismo, em que a IES deixa livre a adesão dos professores ao uso de atividades que utilizem o formato híbrido. (SILVA, MACIEL e ALONSO, 2017, p.111)

Assim, o uso de carga horária a distância nos cursos presenciais, como aponta o resultado da pesquisa de Silva (2016), ainda ocorre de forma bem descentralizada nos cursos e instituições de ensino superior públicas, que concebem seu uso distintamente, bem como tem concepções bem dispares a respeito desse uso como a adoção de um ensino híbrido.

Deste modo, as instituições acabam por reproduzir a falta de uma condução mais precisa sobre definições curriculares que poderiam ser alicerces da institucionalização da educação a distância como modalidade de ensino integrada à instituição. A concepção de vinculação dessa prática à institucionalização da $\mathrm{EaD}$, possibilita uma concepção mais integrada do uso das tecnologias no ensino, seja presencial ou a distância, corroborando para que a EaD passe a integrar, de forma mais orgânica às políticas institucionais e práticas docentes, corroborando, 


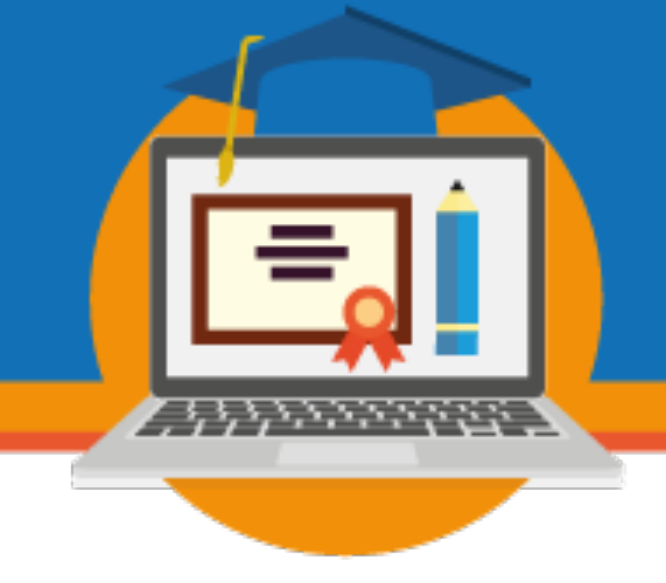

assim, para uma possível integração das políticas das modalidades presenciais e a distância de uma mesma instituição de ensino.

Portanto, no caso do IF Goiano, consideramos que são necessárias análises mais aprofundadas dos gestores, equipe da $\mathrm{EaD}$ na reitoria e dos campi, bem como os docentes e discentes que fazem uso desta perspectiva curricular para identificar mais detalhadamente como essa política institucional tem sido aderida e gerida pelas diversas instâncias da instituição.

\section{Referências}

BRASIL. Decreto $\mathrm{n}^{\mathbf{0}} \mathbf{5 . 6 2 2}$ de 19 de dezembro de 2005. Regulamenta o art. 80 da Lei no 9.394, de 20 de dezembro de 1996 , que estabelece as diretrizes e bases da educação nacional. Disponível em: http://www.planalto.gov.br/ccivil 03/Ato20042006/2005/Decreto/D5622.htm. Acesso em 15 jan. 2020.

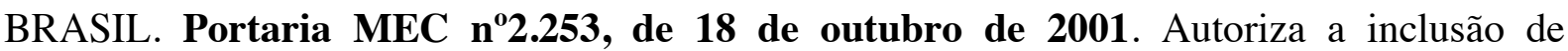
disciplinas não presenciais em cursos superiores reconhecidos. Disponível em: http://cev.org.br/biblioteca/portaria-2253-2001/. Acesso em 15 jan. 2020

BRASIL. Portaria MEC n 4.059, de 10 de dezembro de 2004 (DOU de 13/12/2004, Seção 1, p. 34). Disponível em: http://portal.mec.gov.br/sesu/arquivos/pdf/nova/acs_portaria4059.pdf. Acesso em: 15 jan. 2020.

BRASIL. Portaria MEC $\mathbf{n}^{0} 1.134$, de 10 de outubro de 2016. Revoga a Portaria MEC $\mathrm{n}^{\circ}$ 4.059, de 10 de dezembro de 2004, e estabelece nova redação para o tema. Disponível em: https://abmes.org.br/arquivos/legislacoes/Port-MEC-1134-2016-10-10.pdf. Acesso em: 15 jan. 2020.

BRASIL. Portaria MEC no 1.428, de 28 de dezembro de 2018. Dispõe sobre a oferta, por Instituições de Educação Superior - IES, de disciplinas na modalidade a distância em cursos de graduação presencial. Disponível em: http://www.in.gov.br/materia/lasset_publisher/Kujrw0TZC2Mb/content/id/57496468/do1-2018-12-31-portaria-n-1-428-de28-de-dezembro-de-2018-57496251. Acesso em: 28 jan. 2020.

BRASIL. Portaria MEC n⿳ 2.117, de 6 de dezembro de 2019. Dispõe sobre a oferta de carga horária na modalidade de Ensino a Distância - EaD em cursos de graduação presenciais 


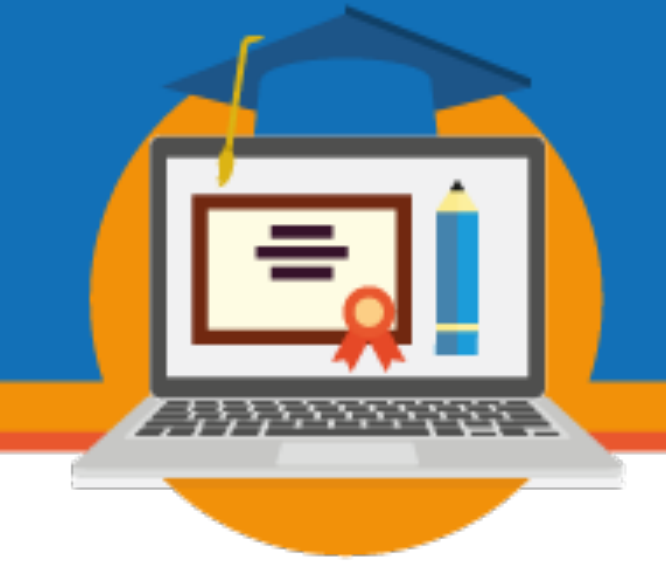

ofertados por Instituições de Educação Superior - IES pertencentes ao Sistema Federal de Ensino. Disponível em: http://www.in.gov.br/en/web/dou/-/portaria-n-2.117-de-6-dedezembro-de-2019-232670913. Acesso em: 28 jan. 2020.

INSTITUTO FEDERAL GOIANO (IF Goiano). Conselho Superior. Regulamento dos cursos de graduação do Instituto Federal de Educação, Ciência e Tecnologia Goiano. Dispõe sobre a organização didático-pedagógica dos cursos de Graduação, no âmbito do IF Goiano. Goiânia: Conselho Superior, 2017a. Disponível em: https://suap.ifgoiano.edu.br/media/documentos/arquivos/Regulamento Gradua\%C3\%A7\%C3 \%A3o Conselho Superior Res.92-2017.pdf. Acesso em 16 jan. 2020.

INSTITUTO FEDERAL GOIANO (IF Goiano). Conselho Superior. Regulamento dos cursos da Educação Profissional Técnica de nível médio do Instituto Federal de Educação, Ciência e Tecnologia Goiano. Dispõe sobre a organização didático-pedagógica dos cursos da Educação Profissional Técnica de nível médio, no âmbito do IF Goiano. Goiânia: Conselho Superior, 2017b. Disponível em: https://suap.ifgoiano.edu.br/media/documentos/arquivos/Regulamento EMT M\%C3\%89DIO-T\%C3\%89CNICO.pdf. Acesso em 16 jan. 2020.

INSTITUTO FEDERAL GOIANO (IF Goiano). Conselho Superior. Regulamento de Educação a Distância do IF Goiano. Dispõe sobre Regulamento dos Cursos da modalidade de Educação a Distância do IF Goiano. Goiânia: Conselho Superior, 2018a. Disponível em: https://suap.ifgoiano.edu.br/media/documentos/arquivos/Regulamento EaD -

IF_Goiano_vers\%C3\%A3o_final.pdf. Acesso em 16 jan. 2020.

INSTITUTO FEDERAL GOIANO (IF Goiano). Conselho Superior. Plano de Desenvolvimento Institucional do IF Goiano - PDI 2019 a 2023. Goiânia: Conselho Superior, 2018b. Disponível em: https://suap.ifgoiano.edu.br/media/documentos/arquivos/39 _PDI 2019-2023 _ _revisado_18-03-2019.pdf. Acesso em 16 jan. 2020.

LENCASTRE, José Alberto. Blended Learning: a evolução de um conceito. In: MONTEIRO, Angélica; MOREIRA, J. António; ALMEIDA, Ana Cristina; LENCASTRE, José Alberto (coords.). Blended learning em contexto educativo: perspectivas teóricas e práticas de investigação. 2.ed. Santo Tirso, Portugal: De Facto Editores, 2013. p. 19-32.

LIMA, Daniela da Costa Britto Pereira. Políticas públicas de EaD no ensino superior: uma análise a partir das capacidades do Estado. Tese (Doutorado) - Universidade Federal do Rio de Janeiro, Instituto de Economia, Programa de Pós-Graduação em Políticas Públicas, Estratégias e Desenvolvimento, 2013. 


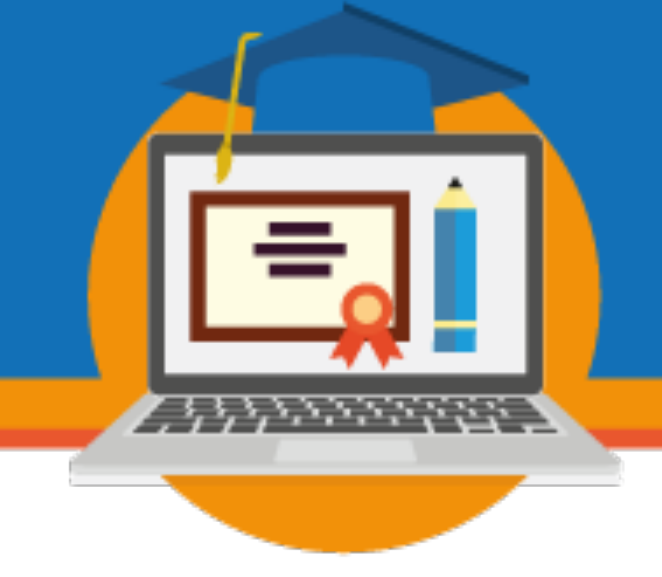

LIMA, Daniela da Costa Britto Pereira. Documento técnico contendo estudo analítico do processo de expansão de EaD ocorrido no período 2002-2012. Produto 02, 2014. Projeto $\begin{array}{llll}\text { Conselho Nacional de } & \text { Educação. } & \text { Disponível }\end{array}$ em: http://mecsrv125.mec.gov.br/index.php?option=com docman\&task=doc download\&gid=16510\&Itemid. Acesso em: 15 jan. 2020.

SEGENREICH, Stella Cecilia Duarte. A invasão silenciosa da EaD nos cursos de graduação presenciais no Brasil: questões de gestão e avaliação. Cadernos ANPAE, v. 1, p. 1-15, 2014.

SILVA, Michele Rejane Coura da. Ensino híbrido nos cursos de graduação presenciais das universidades federais: uma análise da regulamentação. Dissertação (mestrado) Universidade Federal do Mato Grosso, Programa de Pós-Graduação em Educação, Cuiabá, 2016.

SILVA, Michele Rejane Coura da; MACIEL, Cristiano; ALONSO, Kátia Morosov. Hibridização do ensino nos cursos de graduação presenciais das universidades federais: uma análise da regulamentação. Revista Brasileira de Política e Administração da Educação, v. 33, p. 95-117, 2017. 